\title{
Construyendo paz en pareja: una propuesta de intervención integrativa de la terapia narrativa con enfoques feministas y contextuales-relacionales ${ }^{1}$ Construction of peace in couples: a proposal of integral intervention through narrative therapy with feminist and contextual-relational perspectives
}

\author{
Lina María Martínez González*
}

\section{Resumen}

El artículo expone los logros de construcción de paz en una pareja afectada por violencia contra la mujer, obtenidos con la implementación de una propuesta de intervención integrativa mediante terapia narrativa con enfoques feministas postestructuralistas y post/decoloniales, y también con perspectivas terapéuticas contextuales-relacionales.

Se describen los resultados conseguidos a través de las estrategias metodológicas sugeridas por el método narrativo para los momentos de deconstrucción, externalización, exploración de historias alternativas o posibles. Igualmente se destaca la transformación de hechos violentos a partir del reconocimiento de recursos y pautas alternativas para asumir de modo diferente los desacuerdos, en condiciones de continuidad o ruptura de la relación, y de esta manera contribuir a la construcción de paz en la pareja, a partir de una conversación profunda y respetuosa.

\footnotetext{
${ }^{1}$ Artículo producto de la investigación denominada Violencia contra las mujeres en las relaciones de pareja: una aproximación a su comprensión desde la investigación narrativa, realizada como tesis de grado de la Maestría en intervención en relaciones familiares, Universidad de Caldas, Colombia, 2015.

*Trabajadora Social. Especialista y magíster en intervención en relaciones familiares. Magíster en estudios de familia y desarrollo. Candidata a Doctora en Humanidades, línea de género. Profesora del Programa de Trabajo Social de la Universidad del Quindío, Armenia, Colombia. Correo electrónico:1mmartinez@uniquindio.edu.co
}

Recibido: 30 de Abril de 2017 Aprobado: 24 de junio de 2017 ISSN: 0122-1213 (Impreso) ISSN: 2389-993X (En línea) Doi: 10.25100/prts.v\%vi\%i.4543] Prospectiva. Revista de Trabajo Social e intervención social No. 24, julio-diciembre 2017: pp. 149-176 
Palabras clave: Violencia contra las mujeres; Terapia narrativa; Feminismo postestructuralista y post/decolonial; Perspectivas terapéuticas contextuales y relacionales; Construcción de paz en pareja.

\section{Abstract}

This article expounds the achievements obtained through the implementation of a proposal ofintegral intervention consisting of narrative therapy with feminist poststructuralist and post / decolonial approaches and contextual-relational therapeutic perspectives among couples affected by violence against females.

The results obtained through the methodological strategies suggested by the narrative method for the moments of deconstruction, externalization, exploration of alternative or possible histories are described. Furthermore, the article highlights the transformation of violent acts into situations where disagreements are assumed differently through the recognition of alternative resources and patterns, thereby contributing to the construction of peace among partners through meaningful and respectful dialogue.

Key words: Peace building; Violence against women; Narrative therapy; Poststructuralist and post/decolonial feminism; contextualrelational therapeutic perspectives; Construction of peace among couple.

Sumario: 1. Introducción; 2. Referente teórico y conceptual; 3. Material y método; 4. Resultados; 5. Conclusiones; 6. Referencias bibliográficas.

\section{Introducción}

En Colombia, la violencia contra las mujeres en la pareja se expresa en prácticas que subsisten en las relaciones de género ${ }^{2}$, a pesar de las acciones

${ }^{2}$ El informe Forensis de Medicina Legal (2015), indica que durante ese año 2015 se registraron 47.248 casos de violencia de pareja en el país, de los cuales el $86.66 \%$ fueron perpetrados contra mujeres. En el $47,27 \%$ el agresor fue el compañero permanente y en el 29,33\% su excompañero. La Encuesta Nacional de Demografía y Salud (2015) revela que los últimos quinquenios han tenido comportamientos similares en la violencia contra las mujeres.

Prospectiva. Revista de Trabajo Social e intervención social No. 24, julio-diciembre 2017: pp. 149-176 
en materia legal y política ${ }^{3}$ adelantadas por el Estado para su erradicación. Esta situación encuentra su sustento en una estructura social que sigue reproduciendo patrones de comportamiento, creencias y papeles de género a través de los cuales se perpetúan las desigualdades.

En este panorama, el estudio comenzó por considerar que para avanzar en los objetivos de erradicación de esta violencia, se precisa profundizar en el conocimiento de asuntos no contemplados en la investigación tradicional, la cual se orienta hacia el establecimiento de tipologías de agresores y víctimas, y sustenta el enfoque asumido por el Estado colombiano para entenderla e intervenir en ella (el cual puede considerarse victimológico porque parte de una representación de los participantes como victimarios y víctimas, privilegiando acciones de castigo para los primeros y de protección para las segundas).

Tomando distancia de este enfoque, la investigación se interesó por comprender y abordar el problema en la línea de aquellas que privilegian perspectivas alternativas, tales como la perspectiva feminista y las contextuales-relacionales. Éstas se consideran de alta utilidad para los fines de conocimiento planteados, por el hecho de ser críticas frente a la definición y el uso de tipologías de la violencia y de los participantes en ella; también por prestar atención a los aspectos constitutivos del absoluto de la pareja: sentimientos, creencias, acciones pautadas (Caillé, 1992) que producen altos niveles de implicación y cercanía entre las mujeres agredidas y los compañeros sentimentales que ejercen violencia contra ellas, y pueden actuar a favor de la legitimación de las prácticas de maltrato y abuso.

Desde este marco de comprensión del problema, y teniendo en cuenta que la investigación social debe aportar conocimientos útiles a su erradicación, el estudio fue propuesto en un escenario de intervención

${ }^{3}$ El estado colombiano -en coherencia con los compromisos asumidos con la comunidad internacional a través de la suscripción de tratados internacionales como la Convención sobre la Eliminación de Todas las Formas de Discriminación contra la Mujer (1993) y la Convención Interamericana para Prevenir, Sancionar y Erradicar la Violencia contra la Mujer Belém do Pará (1995)- ha avanzado en un cuerpo normativo y político para enfrentar el problema, en el que se destacan la ley 1257 de 2008 y la Ley 1542 de 2012; la Política Pública Nacional de Equidad de Género -que incluye el Plan Integral para garantizar una vida libre de violencias-y la Ley 1761 de 2015. 
desde la terapia narrativa conjunta, integrada con perspectivas terapéuticas contextuales y relacionales así como planteamientos de enfoques feministas postestructuralistas y post/de-coloniales.

Este contexto epistemológico y metodológico reconoce la pertinencia de la terapia para contribuir a la igualdad en la pareja, aun en los casos en que la violencia ha sido pautada a través de un acuerdo implícito rígido (Perrone y Nanninni, 2007) y sus integrantes no identifican formas posibles de detenerla en escenarios de continuidad o ruptura. También resalta el potencial de la integración de la terapia narrativa conjunta con estos enfoques feministas, tanto en la deconstrucción de las posiciones de los integrantes de la pareja que dan cuenta de la legitimación de las desigualdades entre los géneros, que les impide discernir las consecuencias de la violencia para sus vidas, así como en la proyección de formas posibles de afrontarla y fortalecer la paz en la relación consigo mismo/a y con el otro/a .

\section{Referente teórico y conceptual}

La comprensión del problema estuvo apoyada en enfoques posestructuralistas y poscoloniales/decoloniales propuestos por autoras feministas, y por perspectivas contextuales-relacionales planteadas desde la Sociología.

Desde los feminismos post/decoloniales se comprende la violencia contra las mujeres en las relaciones de pareja como una forma exacerbada de dominación masculina, naturalizada como consecuencia del trabajo de construcción simbólica ${ }^{5}$ realizado a través de las normas y las prácticas sociales ${ }^{6}$. Estos coinciden con las explicaciones de Bourdieu (2000) sobre

${ }^{4}$ Estas perspectivas epistemológicas y metodológicas inspiran reflexiones e intervenciones críticas sobre la construcción de paz en la relación personal y con el otro/a, en condiciones de igualdad entre los géneros como un objetivo primordial de la terapia, que permiten estar vigilantes frente a los riesgos de pretender la paz en un marco de desigualdad, que un enfoque neutral del género, acrítico frente al contexto y ciego a las particularidades individuales y de cada pareja, podría presentar.

${ }^{5}$ Denominado por Kaufman (1995) “Trabajo de Género".

${ }^{6}$ Definidas por Foucault (1977) como modos de actuar históricamente construidos, que van ligados a discursos y saberes.

Prospectiva. Revista de Trabajo Social e intervención social No. 24, julio-diciembre 2017: pp. 149-176 
la capacidad de transformación y producción de nuevos discursos y modos de actuar distintos que tiene el trabajo simbólico inscrito en la estructura ${ }^{7}$ de disposiciones y de expectativas, el cual legitima la violencia contra las mujeres (denominada habitus por este autor).

Tales posibilidades de transformación de esta violencia son identificadas en las teorías feministas de Spivak (2009) y Lugones (2011), que comparten con Bourdieu (2000) el reconocimiento de la capacidad de agencia de las mujeres y también de los hombres para transformar las relaciones violentas, ubicándose en una perspectiva decolonial/postcolonial. Este potencial transformador es identificado en la referencia de Spivak (2009) a la textualidad simbólica nueva creada por los subalternos, a través de la cual pueden consolidarse como sujetos contra hegemónicos efectivos. En Lugones (2011), en el concepto de "locus fracturado" a través del cual describe el proceso de oprimir $\rightarrow \leftarrow$ resistir a la diferencia colonial que viven las personas oprimidas.

Estos planteamientos fueron muy importantes para orientar el proceso, frente al cual se asumió -en línea con las autoras citadas, así como con Scott (2011) - una posición crítica del concepto de sistema sexo-género ${ }^{8}$ propuesto por Rubin (1975) a través del cual se da continuidad al pensamiento binario.

En este orden de ideas, se buscó la comprensión, en el marco del proceso de intervención, tanto de las pautas de sujeción a la dominación masculina, como de las prácticas de resistencia a ella, a partir de la aproximación a las posiciones de género de los integrantes de la pareja frente a su experiencia de violencia contra la mujer. Dichas posiciones, entendidas como el modo en que las personas se perciben y actúan respecto a sí mismas, a los otros

${ }^{7}$ Es importante aclarar que la noción de estructura en Bourdieu (2000) y también en Giddens (2000) corresponde a la llamada "teoría de la estructuración" que es diferente a la noción de estructura en el Estructuralismo.

${ }^{8}$ Rubin (1975, p. 97) hace referencia al concepto sistema sexo/género, definiéndolo como "el conjunto de disposiciones por el que una sociedad transforma la sexualidad biológica en productos de la actividad humana, y en el cual se satisfacen esas necesidades humanas transformadas". Esta autora indica que el sustento de las construcciones de género desiguales y jerárquicas se encuentra en la interpretación de una relación binaria entre naturaleza (inferior) y cultura (superior), a través de la cual se ha asociado a las mujeres a la primera y a los hombres a la segunda.

Prospectiva. Revista de Trabajo Social e intervención social No. 24, julio-diciembre 2017: pp. 149-176 
y otras, a partir de procesos particulares de incorporación de principios de visión y de división sexuantes, fueron consideradas posiciones de poder, de un poder que se ejerce, que se encuentra diseminado en toda la sociedad, y del cual todos y todas participamos (Foucault, 1977).

Para realizar la aproximación propuesta, se acudió al feminismo del punto de vista, el cual asume todo conocimiento como situado (Harding, 1987; Hawkesworth, 2006; Grasswick, 2008). El acercamiento a las posiciones de género giró en torno a los significados atribuidos por los integrantes de la pareja a la experiencia de violencia contra la mujer en la relación, en el marco de sus contextos de interacción. De acuerdo con Packer (2013) los significados incluyen los pensamientos y sentimientos de las personas que son producidos en dicho proceso a través del lenguaje (Eagleton, 1983).

Las perspectivas terapéuticas contextuales-relacionales, como la propuesta por Perrone y Nannini (2007), señalan que la violencia no es un fenómeno individual, sino que es la manifestación de un fenómeno interaccional que no puede explicarse solo en la esfera de lo intrapsíquico, sino en un contexto relacional, puesto que es el resultado de un proceso de comunicación particular entre dos o más personas.

La violencia, como parte de los repertorios habituales de intercambios que tienen lugar en una relación de pareja, se manifiesta -en la mayoría de los casos- de forma ritualizada, a través de una especie de contrato denominado "acuerdo implícito rígido", definido como una trampa relacional, donde aparece como una necesidad de mantener el equilibrio entre cada uno de ellos y los otros.

Estos autores señalan que "el consenso al que se llega opera en el nivel bipersonal, pero tiene raíces individuales, ya que se apoya sobre la imagen negativa y frágil que cada uno tiene de sí o sobre circunstancias previas que se registran como tales en la historia individual [...] los miembros de la pareja construyen el consenso y se constriñen a él mediante complejos montajes sintácticos, afectivos y relacionales" (Perrone y Nanninni, 2007, p. 67). Explican que en el consenso implícito rígido se modifica la noción de límite o frontera en los aspectos espacial, temporal y temático: 
En el aspecto espacial, se define (por lo general tácitamente) el territorio donde se admite la violencia. Estos límites establecen los territorios individual y colectivo, íntimo y público, la frontera adentro/afuera, y la presencia o exclusión de terceros... El aspecto temporal señala el momento en el que se desencadenan la agresión y la cronología de los hechos. Son momentos ritualizados en los que es muy probable que irrumpa la violencia. El aspecto temático se refiere a los acontecimientos, circunstancias o contenidos de comunicación que desencadenan el proceso (Perrone y Nanini, 2007, p. 68-69).

En este orden de ideas, estos autores proponen que la interacción violenta sea analizada desde un punto de vista comunicacional, a través del cual es posible acceder al sistema de creencias que las personas construyen para dar sentido a su existencia en relación consigo mismos y con los demás. Aclaran que en los casos de violencia de pareja se encuentran sistemas de creencias con modelos idealizados, que conllevan expectativas inalcanzables de cada uno de los miembros de la pareja, y que para materializar dichas expectativas, el otro puede llegar a ser confinado al silencio o a evitar que muestre las diferencias para que se conforme a su propio sistema de creencias.

En la misma línea, Sluzki (2012) y Ravazzola (2010) plantean que los actos de violencia rompen las premisas básicas de seguridad y respeto recíproco, alterando la coherencia interna que constituye la identidad, generando en ellas consecuencias emocionales, como “...embotamiento emocional... progresivo aislamiento de aquellos miembros significativos de la red social-familia, amigos, vecinos-que contradicen esta versión de la realidad, lo que reduce el contacto social íntimo... riesgo de la repetición del daño [...]." (Sluzki, 2012, p. 4).

\section{Material y método}

La investigación se llevó a cabo en un contexto de intervención establecido a través de nueve encuentros (ocho semanales y uno final realizado un mes y medio más tarde) con una pareja residente en la ciudad de Armenia (Quindío), cuya historia de relación ha estado afectada por este problema. La pareja participante estuvo conformada por una mujer de 
50 años, con un nivel de formación técnica, ocupación como ama de casa y servicios generales (trabajo por días), y su compañero permanente, un hombre de 59 años, con formación de primaria incompleta y ocupación como ebanista.

Al momento de la intervención habían convivido en unión marital de hecho durante 16 años, con su hija de siete años, estudiante de segundo de primaria. La mujer tiene dos hijos de uniones anteriores, y el hombre tiene seis, ninguno de los cuales convive con la pareja. Ambos son alcohólicos recuperados (16 años de sobriedad). La historia de la relación ha estado marcada por la violencia física, verbal y psicológica contra la mujer.

De acuerdo con el compromiso de confidencialidad establecido con los participantes desde el inicio de la investigación, en este documento se hace referencia a ellos a través de nombres ficticios (Gloria para la mujer, Carlos para el hombre, y Ana para la hija).

El método propuesto fue de investigación cualitativa (paradigmas interpretativo y feminista). A partir de una perspectiva metodológica hermenéutica, se planteó una integración metodológica entre la terapia narrativa conjunta (White y Epston, 1990; White, 2004; Payne, 2002), con enfoques feministas postestructuralistas post/decoloniales y perspectivas terapéuticas contextuales y relacionales.

En los diferentes momentos del proceso se implementaron las estrategias metodológicas sugeridas por White (2004) para cada uno de ellos, apoyándose en planteamientos feministas, para animar la externalización de comprensiones, emociones y sentimientos en cuanto a la violencia en la pareja, y orientar la deconstrucción hacia la subversión de realidades y prácticas que se dan por descontadas (y por tanto naturalizan la violencia contra la mujer).

Así, el momento introductorio (encuentro uno) estuvo dedicado a la construcción de un contexto de seguridad, confianza y libertad para la expresión. El momento de deconstrucción (encuentros dos al siete) estuvo destinado a la distinción entre el problema y las identidades de los integrantes de la pareja; la identificación de la forma y el grado en que el problema ha afectado la vida de la pareja, las identidades de sus integrantes y la calidad de su relación; la exploración del posicionamiento de cada 
uno frente a las posibilidades de tomar el control sobre el problema; y la motivación de la incorporación en la identidad, de relatos enriquecidos de las personas sobre sí mismas, el otro/la otra, la vida, los recursos personales $\mathrm{y}$ del entorno.

El momento de cierre (encuentros ocho y nueve) se orientó a afianzar el compromiso con el cambio deseado, evitando generar expectativas inalcanzables, resaltando la importancia de construir la relación como un contexto conversacional colaborativo, como el establecido durante el proceso terapéutico.

\section{Resultados}

La intervención se orientó inicialmente hacia la distinción entre las personas y el problema, en los términos planteados por White y Epston (1990) respecto a que la persona es la persona y el problema es el problema -la persona no es el problema-; es decir, hacia la diferenciación entre la violencia contra la mujer y las identidades de los integrantes de la pareja. Este proceso de externalización motivó la expresión de relatos saturados del problema, a través de comprensiones sobre esta experiencia, así como de emociones y sentimientos asociados a ella, que permitieran a los participantes "bautizar el problema".

- Relatos saturados del problema en la expresión de comprensiones sobre la violencia contra la mujer en la pareja.

Entre los relatos saturados del problema expresados por la mujer, sobresale un fuerte sentimiento de culpa por la instalación de esta situación en su vida, el cual explica las que consideró renuncias a las posiciones $\mathrm{y}$ roles de género socialmente asignados. Ejemplifica este sentimiento haciendo referencia a su negación frente al ejercicio de la maternidad -al delegar a los abuelos la crianza de sus hijos- y frente a algunos mandatos sobre el habitar y el ser del cuerpo femenino, dado que por cuenta del ejercicio de la prostitución consumía alcohol y drogas, y frecuentaba lugares legitimados exclusivamente para la sociabilidad masculina (como bares y cantinas). 
Me mató la curiosidad, y empecé a conocer toda clase de sustancias, luego a permanecer en la calle, a frecuentar bares y hasta a estar en la prostitución. ¿Todo por qué? porque siempre he sido rebelde, siempre me ha gustado el peligro, la vida agitada, y como me gustaba eso, me gustó también él [haciendo referencia al esposo]. Desde que yo lo conocí sabía que era violento, porque lo conoci en medio de una pelea, y no me importó, me gustó el señor y quise estar con él, lo preferí antes que a mi familia y a mis hijos, y seguir con él a pesar de su violencia [...] (Gloria).

Los elementos presentados en este relato constituyen descripciones magras que han sido predominantes en los significados otorgados por Gloria a su situación de violencia, las cuales son entendidas por Geertz (1973) como historias dominantes, saturadas de problemas que oscurecen las relaciones de poder y los actos de resistencia de las personas.

Tales significados explican las posiciones desprovistas de agencia frente a la experiencia de violencia recibida por el compañero, la cual ha sido tolerada durante años aun cuando se rechaza y se lamenta. En este sentido, a través de la creencia de "estar pagando por su pasado con la violencia que vive", la mujer ha sacado el problema del marco de la relación de pareja, y lo ha trasladado al de su propia historia de vida, encubriendo su significado como una concepción de merecimiento personal, y no como un acto no justificable y no tolerable bajo ninguna circunstancia, del cual el único responsable es su compañero.

Este modo de explicar la violencia correspondería a lo que Ravazzola (2010) denomina "anestesia", que esta autora describe como la falta de emoción frente a situaciones dolorosas y entiende como un fenómeno disociativo, a partir del cual se inhibe la comprensión de estas situaciones como un problema cuyas raíces deben buscarse en la dominación masculina, que atenta contra la dignidad y la integridad de la mujer, y en este sentido disminuye la capacidad de tomar decisiones para ponerle fin.

En el hombre se encontró una actitud de des-responsabilización frente a la violencia ejercida contra su compañera, definiéndola como la expresión de su agresividad contenida, la cual, desde su punto de vista, tiene su raíz en la dependencia del alcohol. Esta idea ha encontrado sus correlatos empíricos en la vida de Carlos, en los ataques a sus parejas previas, que 
desde su modo de ver ocurrían a causa de la embriaguez, y en las agresiones a Gloria por la irritabilidad, que considera, es activada de alguna manera por la abstinencia del licor.

Este significado de la violencia como liberación o expresión de la "agresividad contenida", o como "fuerza existente dentro del hombre" es coherente con los mandatos de una masculinidad llamada a afirmar en cualquier circunstancia su virilidad, entendida "como capacidad reproductora, sexual y social, pero también como aptitud para el combate y para el ejercicio de la violencia" (Bourdieu, 2000, p. 39), a través de la cual se naturalizan, y por tanto se justifican modos violentos de relación. Es también consecuente, de acuerdo con Ravazzola, con la instalación de los mandatos de género en los hombres desde etapas tempranas de la vida:

Los varones reciben desde pequeños instrucciones precisas de restringir expresiones emocionales de ternura y, en cambio, son habilitados para la expresión en acciones de emociones de ira y de contrariedad. Esa conjunción les facilita la descarga en acciones de emociones que ellos podrían contener (pero que el consenso social supone que no pueden) sin producir daño (2010, p.3).

En la explicación atribuida por Carlos a los actos de violencia contra su compañera actual, resuena la descripción de este comportamiento como una respuesta activada con los patrones comunicacionales de la mujer, que califica como reiterativos y provocadores:

Ella logra impacientarme tanto con su alegadera, que me desespera y es ahi cuando ya el mal genio me domina y la ataco (Carlos).

Carlos no se reconoció como una persona con predisposición hacia la violencia, sino como un hombre que ha estado expuesto a estímulos que han activado en él esta respuesta; con este posicionamiento se asumió al inicio del proceso como una víctima ante las que consideraba situaciones ajenas a su voluntad, que lo llevaban a dejar de ser la persona que los demás siempre han conocido, perdiendo por instantes los valores y las cualidades que lo han identificado como un hombre educado, respetuoso y tranquilo. 
Desde esta perspectiva, construyó un significado sobre el origen de sus expresiones violentas como hechos excepcionales, que no hacían parte de sus comportamientos habituales en condiciones "normales", sino como respuesta al estilo comunicacional reiterativo y provocador de su pareja:

A mi en todas partes me tienen respeto, la gente me estima, piensan de mí que soy un señor, un caballero, y es que es así, yo, por ejemplo por la casa, saludo si me saludan, no me meto en las cosas de los demás; en el trabajo es igual, llevo tantos años con mi patrón... me conoce como un hombre honrado, trabajador, responsable... con la familia de ella he sido respetuoso, los problemas que ha habido han sido porque ellos han ido a molestarme a mi casa, yo nunca he ido a la casa de ellos a ponerles problema [...] (Carlos).

Estas explicaciones dadas por el hombre sobre la violencia ejercida contra la mujer, en las que demuestra su des-responsabilización frente a los hechos y sus consecuencias, se instalaron en él (en términos narrativos) como "verdades", divorciadas de las condiciones y del contexto de su producción, lo que las hace ajenas a cualquier posibilidad de reflexión sobre asuntos como su papel activo en la escalada de los conflictos, lo injustificado de esta forma de resolución, y las consecuencias de sus actos.

Ante tal ausencia de reflexividad, la violencia contra la mujer se ha constituido en una forma de dominación y control; su uso como una herramienta con la que cuenta el hombre para neutralizar, disminuir o terminar con aquello que le molesta de su esposa, ha sido legitimado en la trayectoria de vida de la pareja, es decir, ha sido reafirmada como una violencia de género.

- Relatos saturados del problema en la expresión de sentimientos y emociones sobre la violencia contra la mujer en la pareja.

Al profundizar en las emociones y los sentimientos destructivos que la violencia ha generado en los integrantes de la pareja, se encontró desde la perspectiva de la mujer, una percepción del profundo daño causado por la violencia ejercida contra ella por parte de su compañero. En uno los encuentros iniciales expresó que la violencia le ha destruido la vida, en muchos sentidos: 
Tengo mucho resentimiento, mucha rabia contra él, porque me da tristeza que él sea así, y me siento impotente porque lo quiero y siento que dependo de él (Gloria).

La expresión de los sentimientos experimentados en los momentos en los que ha sido agredida, conduce a la externalización de la conciencia de un fuerte lazo de dependencia afectiva frente a su compañero:

Siento de todo: cuando me pega me da rabia, me da tristeza, me siento impotente, y cuando ya pasan las cosas me da tristeza pero yo creo que a mí me da miedo que él se vaya, y sigo normal para que todo se calme (Gloria).

Esta confluencia de resentimiento y dependencia en los significados otorgados a la violencia por parte de la mujer, expresada en la rabia frente a la violencia y el miedo a que el agresor se aleje, es explicada por Sluzki en términos de que

Todos los actos de violencia tienen en común el ultraje de las premisas básicas de seguridad y respeto recíproco en tanto seres humanos, del apoyo que esperamos como miembros de una familia, de una comunidad o de la familia humana, generando una experiencia de confusión, una pérdida de la coherencia interna que constituye su identidad (2012. p. 4).

Así, para esta mujer la idea de estar fuera de esta relación significa un riesgo de quedar expuesta a los factores de inestabilidad y desamor de la vida del pasado, los cuales no quisiera enfrentar de nuevo. Desde este horizonte simboliza a su esposo como su salvador frente a esa vida indeseable, al proporcionarle un hogar, unas funciones frente a la familia, y una idea de amor de pareja.

Las conversaciones sobre los sentimientos y emociones identificados antes de cometer las agresiones, condujeron a que el hombre externalizara la existencia de una relación contradictoria entre su auto-percepción como una persona respetuosa y tolerante, y la violencia que ejerce en la relación. Sus expresiones reafirmaron la des-responsabilización frente a sus actos, 
los cuales explicó en términos simbólicos, como fuerzas externas que llegan a él, influenciadas por su esposa:

Antes de llegar a agredirla, yo siento como un mal genio, como una rabia que se apodera de mí, pero no es por nada, es cuando ella empieza a decirme lo mismo, yo le digo que se quede callada, que ya, que no siga con el mismo tema, pero ella sigue [...] (Carlos).

Las emociones presentes durante los momentos posteriores a las agresiones permiten entrever algún nivel de conciencia de su responsabilidad en la violencia ejercida, así como cierta capacidad de reconocimiento frente al daño emocional causado por ésta, no sólo a su compañera, sino también a su hija:

Siempre que esas cosas pasan siento tristeza, me arrepiento de hacer esas cosas porque yo soy consciente de que eso no lo debo hacer, pero no puedo evitarlo ante lo desesperante que se vuelve Gloria cuando empieza a alegar por algo, es desesperante. Además, lo que más pesar me da es con la niña, que ella presencie esos problemas, verme a mi maltratando a la mamá, eso me da más arrepentimiento todavía, cuando ella está, hacerle daño a ella (Carlos).

Estas emociones externalizadas por Carlos, pueden ser entendidas desde los planteamientos de Kaufman (1995) respecto al poder de los hombres como un poder viciado que entraña dolor, aislamiento y alienación. El autor hace claridad en que "esto no significa equiparar el dolor de los hombres con las formas sistemáticas de opresión sobre las mujeres", sino que este poder tiene un costo no solamente para las mujeres, sino también para ellos (los hombres).

Los significados atribuidos por los integrantes de la pareja a la experiencia de violencia contra la mujer, y los sentimientos y emociones externalizados en la construcción de tales significados, de acuerdo con Perroni y Nannini (2007) permitieron reconocer la trampa relacional que constituye el repertorio habitual de intercambios que conducen a dicha violencia, denominado por estos autores "acuerdo implícito rígido”. Así lo 
demostraron las formas como ésta fue bautizada por los integrantes de la pareja:

En el caso de Gloria, ésta fue denominada "sombra u oscuridad" debido a que no sentía que encontraba salida. Carlos la nombró "tormento" dando a entender que tras sus momentos de enceguecimiento y agresión, sentía molestia consigo mismo por su falta de auto-control y por haber cometido una acción incorrecta, y siempre reflexionaba, pensando: "yo actué mal, me sali de control, no debi hacer eso y quedo atormentado con eso".

Estas expresiones "sombra" y "tormento" pusieron en evidencia el poder que ha ejercido la violencia en la relación de pareja, y la ausencia de agencia de los integrantes para salir de ella. Reconocer este poder de la violencia ayudó a los participantes a entender por qué, a pesar de asumirla como un problema del que han deseado salir, la reconocían también como "un callejón sin salida” frente al cual los intentos de superación han sido fallidos, y la esperanza ha disminuido.

- Deconstrucción de la violencia a partir de la externalización de su influencia en la pareja, y de la influencia de sus integrantes en ella.

La magnitud de los sentimientos y las emociones producidos por la violencia entre los integrantes de la pareja, que logró ser reconocida al nombrarlos, al asignarles una nominación, les permitió percatarse de la influencia del problema en su vida y en su relación. Este paso en el proceso terapéutico facilitó hacer visible su actuación como una trampa relacional construida a partir de la sujeción de ambos al cumplimiento de determinados papeles en los diferentes momentos del ciclo de la misma, y de la actitud de sometimiento ante su presencia en sus vidas, pese a calificarla como una interacción destructiva. Es decir, les ayudó a darse cuenta que el poder de la violencia les impide mantener el equilibrio personal y relacional.

El reconocimiento de tal poder emergió, por supuesto, en una conversación reflexiva sostenida con los participantes en el proceso de la entrevista, la cual constituyó un escenario propicio para que sus manifestaciones en la relación fueran traídas a escena por ellos, a partir de preguntas direccionadas a la externalización del efecto de la violencia en sus vidas y en su relación. El proceso de deconstrucción propuesto estuvo orientado por el planteamiento de Ravazzola respecto a que las personas: 
somos diferentes en contextos diferentes, y esta mirada contribuye a ubicarnos como responsables de cambiar, en lo posible, los contextos en los que se perpetúan algunas conductas que no deseamos. Esta manera de pensar también nos habilita a buscar cómo relacionarnos con los protagonistas de los circuitos familiares en los que hay violencia, considerando la singularidad de cada situación y las posibilidades de cambio de cada uno/a (2010, p. 4).

Las conversaciones establecidas en torno a este planteamiento condujeron a que Carlos, aunque en los encuentros iniciales continuara significando sus actos de violencia como "estallidos de ira ante la irritación producida por su esposa", paulatinamente fuera transformando, restando legitimidad al uso de la violencia, avanzando en la comprensión de que tenía el compromiso de buscar otras formas de "expresar la ira que se apoderaba de él'. Este avance fue posible en el proceso previamente mencionado, de reconocimiento de la violencia como un mecanismo de control hacia la mujer validada por el sentimiento de superioridad masculina y consentida por largo tiempo en nuestra cultura, pero inaceptable dentro de las formas de interacción y de resolución de los conflictos en la sociedad actual.

Tales conversaciones facilitaron la comprensión de algunos factores determinantes en el sometimiento de Gloria a la violencia, no obstante el dolor y el temor que le produce, puestos en visibilidad en la externalización de las razones para desear permanecer en la relación, significada como la oportunidad de preservar la familia. Uno de ellos, que ha influido con fuerza en esta actitud, es haber sido madre por tercera vez; esta vivencia, respaldada por un lado en el sentimiento de culpa generado por la renuncia al ejercicio de la maternidad con sus dos hijos mayores, y por el otro en la creencia de que los hijos de los alcohólicos y de los adictos son inestables, fortaleció sus ideas frente a la maternidad como una función femenina fundamental, para cuyo cumplimiento exitoso considera primordial la crianza compartida por el padre y la madre, como fuentes de afecto, protección y autoridad.

Otro factor, asociado directamente al anterior, es el reconocimiento de las fortalezas de Carlos como padre, el cual ha ratificado la decisión de 
Gloria de permanecer en la relación, sustentada en diferentes aspectos de lo que considera un ejercicio adecuado del rol paterno:

Es un buen cumplidor de sus responsabilidades económicas y es una figura de autoridad firme para Ana, que es una niña tan rebelde y difícil. Además, quiere mucho a la niña, y ella a él, le gusta mucho compartir con su papá (Gloria).

No obstante las razones para conservar la familia, soportadas principalmente en el beneficio percibido para su hija de ser socializada en un ambiente familiar con un padre presente, Gloria se mostró consciente de que la violencia no debe hacer parte de la interacción propiciada por su compañero en el cumplimiento de su rol parental y conyugal; así, logró expresar algunas consecuencias negativas que esta violencia ha causado en la relación paterno-filial y en la vida emocional de la niña:

A Ana le afecta mucho ver que el papá me maltrata, y también que le pegue a ella, porque él con rabia le pega hasta a ella, y fuerte; la niña le tiene miedo, aunque él es buen papá, yo no voy a decir que no, él la quiere mucho, es muy responsable, la cuida mucho, y ella también lo quiere, lo adora, es muy apegada a él (Gloria).

Los sentimientos frente a la paternidad fueron fundamentales en la movilización de las historias de des-responsabilización respecto a la violencia asumidas por Carlos al inicio de la intervención narrativa, las cuales indicaban la ausencia de agencia en cuanto a la transformación de la violencia -en la continuidad o en la ruptura de la relación de pareja-, demostrada en una actitud de conformismo ante ésta, expresada en el siguiente relato:

No he pensado en irme de la casa, o dejarla, porque primero obviamente yo a ella la quiero, además ella tiene cosas muy buenas, primero que todo es muy amorosa, es una gran mujer y persona, aunque me incomodan los celos, ese hostigamiento que mantiene sobre uno, y cuando me dice la misma cosa diez veces, yo me lleno de rabia y ahí es donde es el problema, porque si ella empieza y yo no le pongo cuidado o me voy a la esquina, 
evito el problema, pero si yo le digo, hablemos, es que con ella no se puede hablar [...] (Carlos).

A la transformación de esta actitud contribuyeron las conversaciones acerca de sus sentimientos como padre, las cuales activaron el reconocimiento de los efectos negativos de la violencia en la hija, y la expresión del tipo de relación que deseaba tener con ella:

Sí, a mí me duele causarle daño a la niña, hacer que se sienta triste y asustada, soy consciente que le hago daño [...]. Entiendo que no es bueno que me vea alterado, luego tranquilo, pues eso le puede causar miedo, puede llegar a tenerme miedo, y pensar que yo soy ese tipo de persona, cuando no lo soy (Carlos).

En este punto de la intervención, la implementación de técnicas como el "otro internalizado" permitió que las historias dominantes en las posiciones de género de Carlos fueran confrontadas con aquellas insurrectas que visibilizaron la magnitud del daño causado a su esposa y en especial a su hija, y que le permitieron salir de la zona de confort que le proveía la "fortaleza masculina", autorizándole a externalizar el dolor que a él también le generaba agredir a su esposa.

En este momento del proceso logró concretar su deseo de conservar a su familia, así como su compromiso con la continuidad de la vida de pareja -y parental-, libre de la violencia contra la mujer, de la cual llegó a asumirse como responsable. Para ello, fue fundamental todo el trabajo en torno a la externalización del problema, a través del cual éste fue comprendido como una acción independiente su identidad como hombre, esposo, padre, etc.

En cuanto a las posiciones de género de Gloria, se encontró, retomando a Ravazzola (2010), que el amor, descrito en términos de plenitud, decisión y esperanza, ha constituido una fuerte razón para dar sentido al deseo de continuar con la vida en pareja:

A mí me gustó el señor desde que lo vi, me gustaba su compañia, me decidí a estar con él, preferí estar con él que con mis hijos y con mi familia, entonces sí veo que hay que luchar por estar mejor, por sanar el dolor (Gloria). 
El proceso de deconstrucción de las posiciones asumidas por los integrantes de la pareja frente a la relación -descritas en los párrafos anteriores- estuvo orientado desde los planteamientos de Bourdieu, quien invita a no utilizar argumentos que ratifican la dominación, "consistentes en atribuir a las mujeres la responsabilidad de su propia opresión, sugiriendo como se hace a veces, que ellas deciden adoptar unos comportamientos de sumisión [...] gracias a una especie de masoquismo constitutivo de su naturaleza" (2000, p. 32). Por el contrario, se tuvo en cuenta que:

esta construcción práctica, lejos de ser un acto intelectual consciente, libre y deliberado de un "sujeto" aislado, es en sí mismo el efecto de un poder, inscrito de manera duradera en el cuerpo de los dominados bajo la forma de esquemas de percepción y de inclinaciones (a admirar, a respetar, a amar, etc.), que las hacen sensibles a expresiones simbólicas del poder (Bourdieu, 2000, p. 33).

En el marco de la comprensión aportada por Bourdieu respecto a las posiciones asumidas por las mujeres víctimas de la dominación masculina, la intervención terapéutica apuntó a comunicar a Gloria la comprensión construida por la profesional frente a las razones que han sustentado su decisión de continuar en la relación de pareja, pero acompañándola del reconocimiento de sus fortalezas (tales como la fuerte voluntad frente al consumo de alcohol y drogas, el compromiso de brindar las mejores condiciones posibles a su hija, las actitudes de liderazgo comunitario, entre otras).

A través de la búsqueda y la ampliación de excepciones y logros inesperados fundamentados en tales fortalezas, se logró que estas historias subyugadas se fueran convirtiendo en historias robustas, que contradijeran aquellas dominantes que limitaban la agencia de la mujer frente al problema. Por ejemplo, las etiquetas de inseguridad, debilidad y dependencia asociadas a la idea de "ser alcohólica"; la exposición "voluntaria" a la violencia entendida como una forma de pagar sus errores del pasado; o la idea de que la familia nuclear es condición más importante para el bienestar de la hija, que las relaciones igualitarias y respetuosas entre sus padres. 
- Identificación de logros aislados y desenlaces inesperados.

En este momento se motivó a la pareja a explorar formas cómo han afrontado los conflictos de la relación, con estrategias distintas a la violencia. Ésta, de acuerdo con las comprensiones expresadas por ellos, surge de las dificultades de comunicación frente a las cuales fue instalada como la forma convencional de resolver los conflictos ocasionados por el circuito de exasperación de Carlos a partir de la insistencia de Gloria en cierto tipo de mensajes y pauta comunicacional.

El reconocimiento de la fuerza de las dificultades de comunicación, en la instalación de la violencia en la relación, ratificó la importancia del enfoque de terapia narrativa, basado en la construcción de contextos conversacionales colaborativos, en los que, de acuerdo con Ravazzola, se enfatiza en el fortalecimiento de las capacidades de los participantes para "saber pedir, saber preguntar, saber asumir las necesidades propias, reconocer y agradecer lo que otro nos da [...]. Acciones comunicativas muy necesarias para crear contextos colaborativos que en general no están en el repertorio de los miembros de familias en las que el abuso es una práctica repetitiva" (2010, p. 4).

En este orden de ideas, aunque en un primer momento no hubiese sido posible reconocer con amplitud momentos excepcionales y recursos en la pareja, la conversación en torno a estos permitió visibilizar estrategias que, de acuerdo con los relatos de los participantes, de ser activadas, serían de gran utilidad para hacer frente a la violencia contra la mujer.

Al comienzo de tal exploración, la mujer solo identificó que la violencia no se consumaba cuando ella decidía "quedarse callada" ante la agresividad percibida en su compañero. Él, por su parte, manifestó que "irse de la casa" era la única forma de evitar las agresiones. No obstante, ambos reconocieron que esta estrategia tenía una utilidad limitada desde el punto de vista temporal, porque la rabia quedaba contenida en ambos, más el miedo en Gloria, con lo cual las agresiones ocurrían inevitablemente.

Las explicaciones para evitar la violencia a través de estas actuaciones permitieron hacer visible su baja efectividad frente a la pauta interaccional instaurada, y ampliar su descripción a partir de la ilustración realizada por 
cada uno de sus acciones y emociones en determinados momentos del ciclo:

A mí me da mucha tristeza, y rabia, y en el momento no me importa que me pegue, pero a veces opto por quedarme callada para evitar, pero no por miedo sino por cansancio de esta situación (Gloria).

Siempre que esas cosas pasan siento tristeza, me arrepiento de hacer esas cosas porque yo soy consciente de que eso no lo debo hacer (Carlos).

Dado que el único momento singular identificado por él era "irse" para "evitar" la violencia, se realizaron preguntas sobre lo que ocurría en él y en el entorno cuando optaba por hacerlo y evitar la violencia, qué acompañaba la decisión de quedarse y atacar a su esposa, encontrando en sus respuestas, relatos enriquecidos que facilitaron apreciar que el cambio era posible. Entre tales respuestas fueron frecuentes las referencias enunciadas en momentos anteriores del proceso respecto a "ser un hombre tranquilo", percibido por los demás como "un caballero"; éstas fueron presentadas como evidencias ratificadas por él mismo, y reconocidas con mayor claridad en esta fase de la intervención, respecto a que "la ira se apoderaba de él" pero que no "era él”, puesto que no ha sido un aspecto relevante de su identidad por la que otras personas lo reconocen.

Teniendo en cuenta los aspectos positivos sobre sí mismos, el otro o la otra, y la relación, expresados al relatar las comprensiones, emociones y sentimientos producidos frente a la violencia, la búsqueda de momentos excepcionales fue encaminada hacia la incorporación en la identidad, de los relatos enriquecidos, y a la comprensión de éstos como expresiones de fortalezas que no han sido creadas durante la intervención ni les han sido aportadas desde el exterior, sino que han sido parte de los valores, principios y emociones que no han sido parte activa de su interacción en la pareja y en la familia. Con esto, a la vez se les otorgó la responsabilidad de actuar con compromiso frente al cambio, que representaban estos nuevos descubrimientos sobre sí mismos y sobre el otro/a.

El trabajo con Gloria se orientó a revaluar la creencia de ser una persona agresiva e insegura como consecuencia de su historia de consumo, mostrándole relatos enriquecidos sobre sí misma, como la capacidad 
para ayudar a otros (familiares, vecinos, instituciones), aptitud por la cual ha sido valorada por las personas de su entorno; también se hizo alusión a su fortaleza para conservarse por años alejada del consumo de alcohol y drogas, aún sin asistir a grupos de autoayuda y sin consumir los medicamentos psiquiátricos que le han sido recetados. Con este trabajo se logró aportar al fortalecimiento de su conciencia de merecimiento y su concentración en lo que desea para su presente y para su futuro, dando pasos en la reconciliación con su pasado.

La motivación frente a otras opciones para afrontar el problema externalizado, permitió que la pareja pusiera en práctica estrategias comunicativas acordadas durante el proceso de intervención, para pausar la pauta violenta, debilitarla, y no ser controlados por ella. Estos logros fueron narrados en actividades de esparcimiento compartidas, en las cuales las dificultades asociadas al guión de comunicación que históricamente ha detonado la violencia, fueron resueltas de forma distinta a las posiciones acostumbradas (callar/irse):

Nos fuimos para ese paseo, todo iba muy bien, pero yo pregunté algo de una cuota que nos tocó dar, él me dijo como siempre "cállese, no diga eso que las cosas no son así". Yo no me alteré en ese momento, sino que le dije que recordara que me molesta que me calle, y más delante de la gente, y que no tenía por qué hacerlo porque yo hubiera entendido mal [...]. Él como que reaccionó y me explicó, tranquilamente, me sacó de la duda, y pudimos estar tranquilos el resto del rato en el paseo [...] (Gloria).

Ella me hizo reflexionar que estaba mal que yo la callara delante de la gente, me acordé que a ella eso le duele mucho, así para mí sea una forma de hablar, yo estoy acostumbrado a decirle así, pero sé que tengo que cambiar eso [...]. Finalmente los dos nos calmamos y seguimos bien, la verdad la pasamos bien, y la niña también [...] (Carlos).

También se empezaron a incorporar momentos de conversación sobre la relación y sobre el proceso de intervención, en los que la pareja valoró positivamente que Carlos no cometiera agresiones durante los dos meses de participación en el mismo. En estas conversaciones, se reconocieron los cambios en la vida de pareja y de familia, que reportaron mayor experimentación de alegría, paz y bienestar, también compromiso para 
mantener a la violencia contra la mujer fuera de la relación. Así narraron los participantes estos momentos:

Nosotros nos ponemos a hablar y decimos, vea lo bueno que estamos viviendo, ya sin esa tensión de estar agarrados, diciéndonos las cosas. Notamos que ella ha dejado de decir las cosas con tanta violencia y agresividad, y yo también soy capaz de hacerle ver que no necesita decirme más, que yo le entendí, y le explico [...]. Siempre que me va a dar esa ira, me acuerdo de lo que hemos trabajado acá, y me calmo [...]. Me doy cuenta de que hemos podido cambiar, y que no nos podemos tirar en lo que hemos logrado [...] (Carlos).

Esta mañana conversábamos que ya hoy la última sesión, que tanto bien que nos hizo estar en este proceso, porque ya estábamos muy mal, yo por lo menos estaba muy cansada [...]. Yo veo que los dos hemos cambiado, a él ya se le puede hablar sin que conteste exasperado, ya no se pierde, por lo menos llama una vez al día del trabajo, yo a veces voy a verlo jugar tejo [...]. Esas saliditas que hemos hecho juntos nos han ayudado a oxigenarnos, a salir de la rutina [...]. Aunque todavía hay mucho por mejorar, compartir más, tener más amor y armonía, pero hemos avanzado, vamos bien [...] (Gloria).

La reflexión sobre las ganancias emocionales percibidas en los momentos excepcionales, en los que los integrantes de la pareja lograron evitar los actos violentos, contribuyó a rebatir la concepción sobre las supuestas ganancias obtenidas al preservar la pareja sin hacer frente a la violencia y a sus efectos. El reconocimiento del bienestar, la paz y la alegría que ha tributado la evitación de la pauta violenta, permitió a los integrantes de la pareja (en especial a la mujer) darse cuenta de la importancia de estos estados en su vida, e incentivó su posición como agente frente a la transformación de la violencia de pareja de la que ha sido víctima.

-Acompañamiento a los integrantes de la pareja a dar pasos constructivos hacia otras formas de sentir, pensar y vivir

Durante la fase final del proceso (acompañamiento y seguimiento al cambio), se reafirmó la materialización de los avances identificados en las interacciones cotidianas durante las últimas sesiones. Se connotaron positivamente los logros frente a los momentos de tensión, las iniciativas 
para fortalecer los espacios de unión, las formas de comunicación con las que se valida a la pareja y se le reconoce la importancia en la vida del otro/a, y los efectos positivos que tales cambios producen en la hija.

Se hizo clara la necesidad de fortalecer la confianza en el otro/a para comunicarle sentimientos, emociones, preocupaciones, etc., incrementar la interacción en espacios distintos al hogar y establecer condiciones para la comunicación. Se incentivó en Carlos la internalización de la posición como agente en la toma de control de esta pauta relacional sumamente destructiva en su entorno de pareja y familia. Se insistió en la exploración de momentos excepcionales en las cuales él pudo controlar la ira y no dejarse dominar por ella.

Se propuso concertar un momento de encuentro semanal, que tuviera en común con las sesiones terapéuticas, ser un espacio en el cual los integrantes de la pareja continuaran expresando tanto lo que les molesta como lo que les agrada de su pareja, bajo las mismas condiciones de respeto establecidas para el escenario de intervención.

Mes y medio después de la octava sesión, se realizó un último encuentro en el que se reafirmó el acompañamiento, y se animó a la pareja a continuar en la ruta hacia el cambio. En este momento de cierre, se hizo memoria sobre los diferentes rumbos que pudo tomar la relación, entre los cuales como pareja se optó por continuar juntos, luchando por transformar la violencia contra la mujer.

A través de preguntas y comentarios que invitaron a la reflexión sobre los avances y los retrocesos, las posibilidades y las dificultades al asumir este reto, se afianzó el compromiso con el cambio deseado, evitando generar expectativas inalcanzables. Se recordó la importancia de continuar construyendo la relación como un contexto conversacional colaborativo, como el establecido durante el proceso terapéutico, reconociendo el papel decisivo de la comunicación en la generación y disolución de la violencia (Ravazzola, 2010), y en la construcción de la paz, la tranquilidad y el bienestar anhelado para la relación. 


\section{Conclusiones}

El trabajo de deconstrucción de los sentimientos y emociones producidos por la violencia contra la mujer entre los integrantes de la pareja, desde la perspectiva metodológica implementada, constituye un proceso de alta utilidad para los fines de toda intervención en este tipo de violencia: su erradicación de la vida de las personas, en condiciones de continuidad o de ruptura de la relación.

La implementación de las estrategias metodológicas sugeridas por White (2004) con el apoyo de planteamientos provenientes de enfoques feministas postestructuralistas y post/decoloniales, permite movilizar los relatos saturados de problemas para identificar momentos excepcionales en los que la violencia no ha estado presente en las interacciones ni ha perturbado la paz personal y relacional.

El descubrimiento de tales momentos, reconociendo -con los aportes brindados por perspectivas terapéuticas contextuales-relacionales- que las fortalezas presentes en ellos provienen de la forma particular como la pareja ha estructurado la vida cotidiana, llegan a constituir oportunidades para el cambio, entendido como la orientación hacia otras opciones para afrontar el problema externalizado, en condiciones en las que el compromiso de los participantes se oriente hacia tales fines.

En la experiencia de intervención con la pareja referenciada, la culpabilidad sentida por la mujer por la negación a asumir posiciones coherentes con los mandatos de la dominación masculina, fue reconocida como una forma predominante de justificar ser víctima de violencia en la pareja, la cual ratificaba la instalación de la "actitud natural" (Harding, 1987) en dichas posiciones.

En el caso del hombre, se encontró que las posiciones de desresponsabilización ante la violencia ejercida en la relación, también están sustentadas en la "actitud natural" dominante en su significado de la violencia como expresión de la virilidad masculina. En este marco de comprensión, la violencia es ubicada en el plano de lo inevitable, trasladando a la mujer la responsabilidad de que "emerja" esta "fuerza contenida" en él, por su "naturaleza masculina". 
Tales posiciones han sido reforzadas con las "ganancias" percibidas frente a la permanencia en pareja. En el caso de la mujer, su lugar en la relación ha sido establecido desde una alta "dependencia afectiva", otorgándole a ésta gran poder respecto a la seguridad emocional (para sí y para su hija), y frente al deseo por construir una relación amorosa satisfactoria. Las experiencias del pasado han reforzado la "dependencia afectiva frente a la relación", incrementando el sentimiento de fragilidad respecto a la violencia, y de parálisis frente a la posibilidad de tomar decisiones que le permitan salir de ella.

El hombre ha establecido significados en relación con las ganancias en la pareja a partir de los estereotipos de género que, desde su perspectiva masculina sobre la complementariedad correspondiente a lo femenino, han sido cumplidos satisfactoriamente por parte de la mujer (ser buena mamá, amorosa, atenta a las necesidades de su familia), los cuales son significados como fuente de un hogar estable y de una crianza adecuada para su hija, liderada por su compañera desde el punto de vista del cuidado y de la orientación.

En este contexto, la terapia narrativa, integrada con enfoques feministas postestructuralistas y post/decoloniales y perspectivas terapéuticas contextuales y relacionales, constituyó un método que permitió abrir posibilidades para establecer una conversación profunda en medio de la cual los significados, fueron susceptibles de deconstrucción y transformación al ser reconocidos y cuestionados.

El proceso de deconstrucción y externalización, así como la exploración de historias alternativas o posibles llevado a cabo en las sesiones de entrevista con orientación narrativa, cuando pasó por las emociones y los sentimientos, logró incrementar las posibilidades de tomar decisiones de cambio frente a la violencia como un acto producido y productor de emociones negativas y destructivas para sí mismos y para su entorno, aportando a la transformación de los horizontes de visión y de acción de las personas participantes y de la pareja, hacia posiciones de género que hagan posible la construcción de paz en la relación personal y con el otro/a, en condiciones de igualdad entre los géneros. 


\section{Referencias bibliográficas}

Bourdieu, P. (2000). La dominación masculina, Barcelona: Editorial Anagrama.

Eagleton, T. (1983). Literary Theory, Gran Britain: Library of Congress Cataloging-in-Publication Data.

Foucault, M. (1977). Historia de la sexualidad: 1- La voluntad del saber. Bogotá: Siglo XXI editores.

Geertz, C. (1973). The interpretation of cultures: Selected essays. United States of America: Basic books. Recuperado de https://monoskop.org/images/5/54/ Geertz_Clifford_The_Interpretation_of_Cultures_Selected_Essays.pdf

Giddens, A. (2000). Modernidad e identidad del yo: el yo y la sociedad en la época contemporánea. Barcelona: Peninsula.

Grasswick, H. (2008). Feminist Social Epistemology. California: The Standford encyclopedia of Philosophy.

Harding, S. (1987). Feminism and methodology. Bloomington: Indiana University Press.

Hawkesworth, M. (2006). Feminist Inquiry. From Political Conviction to Methodological Innovation. New Jersey: Rutgers University.

Kaufman, M. (1995). Los hombres, el feminismo y las experiencias contradictorias de poder entre los hombres. En Arango, L.; León, M. y Viveros, M. (comps.) Género e identidad. Ensayos sobre lo femenino y lo masculino (pp. 123-146). Bogotá: Tercer Mundo.

Lugones, M. (2011). Hacia un feminismo descolonial. Revista La Manzana de la Discordia, 6(2), 105-119.

Packer, M. (2013). La ciencia de la investigación cualitativa. Bogotá: Ediciones Uniandes.

Payne, M. (2002). Terapia narrativa. Una introducción para profesionales. Barcelona: Paidós.

Perrone, R. y Nannini, M. (2007). Violencia y abusos sexuales en la familia. Buenos Aires: Paidós.

Ravazzola, M. (2010) Violencia familiar: Actualización de recorridos teóricos y técnicos desde la terapia sistémico - relacional y perspectivas que incluyen estudios de género. Buenos Aires: REDPIAF.

Rubin, G. (1975). El tráfico de mujeres: notas sobre la "Economía Política" del sexo. Revista Nueva Antropología, 30(8), 94-145.

Scott, J. (2011). Género: ¿Todavía una categoría útil para el análisis? Revista La manzana de la discordia, 6(1), 95-101.

Sluzki, C. (2012). Las "narrativas" en la terapia con víctimas de violencia. Recuperado de http://psicologossalta.com.ar/ las-narrativas-en-la-terapia-con-victimas-de-violencia/ 
Spivak, G. (2009). In other words. USA: Wiley-Blackwell.

White, M. (2004). Guías para una terapia familiar sistémica. Barcelona: Gedisa. White, M. y Epston, D. (1990). Medios narrativos para fines terapéuticos. Barcelona: Paidós.

Cómo citar este artículo:

Martínez-González, L. M. (2017). Construyendo paz en pareja: una propuesta de intervención integrativa de la terapia narrativa con enfoques feministas y contextuales-relacionales. Prospectiva, 24, 149-176. Doi: 10.25100/prts.v\%vi\%i.4543 